\title{
The Case Analysis of the Permeability of Distributed Grid-connected Photovoltaic Generation
}

\author{
Peng Peng, Yuying Shao, Xiaoyan Zhu, Xiaodong Lou, Guoqin Yu, Yongzhong \\ Chen, Jian Li and Wei Yu \\ State Grid Shanghai Municipal Electric Power Company \\ Shanghai, China \\ E-mail: pengwyw@hotmail.com
}

\begin{abstract}
Keywords: distributed photovoltaic generation, grid-connected, permeability
Abstract. Distributed generation could be used as a useful supplement to the power grid, which was also the basis of the development of global energy internet. However, a large amount of clean energy integrated into power grid would bring huge challenges to the traditional power grid. In this paper, the state of distributed grid-connected photovoltaic generation in Songjiang District of Shanghai was analyzed. Then taking a distributed grid-connected photovoltaic generation project as an example, on the basic of the actual data of load and photovoltaic power, a mathematical model was built by matlab software in order to discuss the relationship between the permeability of distributed grid-connected photovoltaic generation and traditional grid units coordination ability. The utilization and installed capacity of the photovoltaic generation were calculated at different permeability levels, which provided construction suggestions for optimizing the configuration of photovoltaic and improving the ability of the system admitting the photovoltaic.
\end{abstract}

\section{Introduction}

Now the $90 \%$ load is provided by the grid, so any faults on the grid should make an impact on the entire grid [1]. The peak of distributed photovoltaic generation fits the load peak well, which can effectively alleviate the pressure of a surge in electricity demand, especially for Shanghai that was a typical load-centralized city with a short radius of power supplement. Distributed photovoltaic generation is economical and effective, which can be used as a useful complement for the load-centralized grid [2]. More than half of the power grid was supported by distributed generation in Germany, while the daily peak of the load in Italian had been cut by $20 \%$ due to the distributed grid-connected generation, and the daily peak of the load in Greece was even completely cut [3]. However, because distributed photovoltaic generation are greatly affected by climate, the poor stability would greatly influence the safe and stable ability of the grid if a large amount of distributed photovoltaic generation connected into the grid. So in this paper, our group built a model to analyze the permeability of distributed grid-connected photovoltaic generation under the limitation of traditional grid units coordination ability.

As one of the most successful country on the development of distributed photovoltaic generation, distributed generation has become most important energy system in Germany, among which distributed photovoltaic generation accounted 90\% [4]. According to the latest statistics of the State Grid Corporation, until July 2015, the installed capacity of distributed grid-connected photovoltaic generation reached 10.46GW and that was 26.72MW in Songjiang District of Shanghai until 2015 [5], which accounts for only $3.32 \%$ of the daily maximum load (2053MW) in 2015 which accounts for only $3.32 \%$ of the daily maximum load (2053MW). If calculated by the current maximum photovoltaic conversion efficiency of $23.8 \%$, the permeability of distributed grid-connected photovoltaic generation is less than $0.3 \%$ in Songjiang area of Shanghai. Compared with the highly permeability levels of Germany and the United States, it is a very small value. Therefore, for the permeability of distributed grid-connected photovoltaic generation, its volatility and intermittent on the grid can almost be ignored. 
In recent years, various policies and norms of photovoltaic plants have transferred to that of distributed photovoltaic generation constantly and it is improving and perfect in China. Until August 2016, the number of home users of the photovoltaic generation in Songjiang District of Shanghai had reached 516, as shown in Fig. 1. The number of home users appeared explosive development even in 2015 and the growth rate was as high as $167 \%$ from February to December in 2015. The fitting curve of the number of home users displayed the trend of exponential growth and it was predicted that number of home users of the photovoltaic generation in Songjiang District will likely breakthrough 2297 at the end of 2017. Now the distributed photovoltaic generation has been recognized by more and more residents, Therefore, the number of users of the photovoltaic generation will continue to boom and distributed photovoltaic generation will enter a peak period of development in the period of " 13 th Five Year" planning.

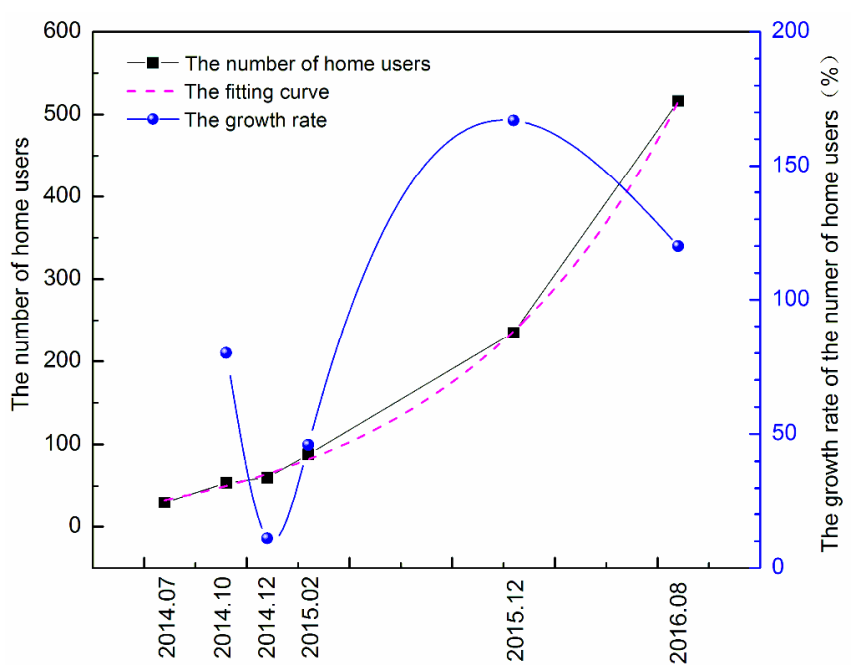

Fig. 1 The number and the growth rate of home users of the photovoltaic generation in Songjiang District

\section{Establishing mathematical model}

Take a project of distributed grid-connected photovoltaic generation in Shanghai as an example. In this paper, the state of load and photovoltaic power on a typical day were selected as a representative case, just because photovoltaic generation is related to the climate and the environment. The system respectively recorded the data of load and photovoltaic power every 1 hour.

(1) Related concepts

The permeability of distributed grid-connected photovoltaic generation: The actual consumed capacity supplied by distributed photovoltaic on that day accounts for the percentage of the capacity of the total load in the same day [6,7],

$$
P V \text { permeability }=\frac{\sum_{t=1}^{24} y_{t}}{\sum_{t=1}^{24} f_{\text {load }}\left(x_{t}\right)} \times 100 \% \text {. }
$$

$f_{\text {load }}\left(x_{t}\right)$ is the consumed capacity of load at $t$ time, and $y_{t}$ is consumed capacity supplied by distributed photovoltaic at $t$ time.

The utilization of distributed grid-connected photovoltaic generation: The ratio of the actual consumed capacity supplied by distributed photovoltaic on that day with the actual photovoltaic power. 


$$
P V \text { utilization }=\frac{\sum_{t=1}^{24} y_{t}}{\sum_{t=1}^{24} f_{P V}\left(x_{t}\right)} \times 100 \%
$$

$f_{P V}\left(x_{t}\right)$ is the actual photovoltaic power at $t$ time.

(2) Basic assumptions

The other factors that affect traditional grid units coordination ability were not taken into account and the coordination ability was limited to $50 \%$ 100\%;

The operating loss of photovoltaic generation system and environmental factors were not considered and the relevant parameters of the photovoltaic generation system maintained consistency in this paper

The system in this paper was considered as an independent power supplement system, which was constructed by load, photovoltaic generation and traditional grid units.

(3) Establishing model

Based on the above assumptions, the permeability model of distributed grid-connected photovoltaic generation was established. According to the actual data of load and photovoltaic power on a typical day in 2015, the utilization and the permeability of photovoltaic were calculated in the conditions of allowing power-discarded of photovoltaic systems. The relationship between the utilization and permeability level of photovoltaic generation was obtained by increasing the install capacity of the photovoltaic system. At the same time, traditional grid units coordination ability was adjusted, and a series curves of the impact of the permeability of distributed photovoltaic on traditional grid units coordination ability were displayed. The flow chart was shown as Fig. 2.

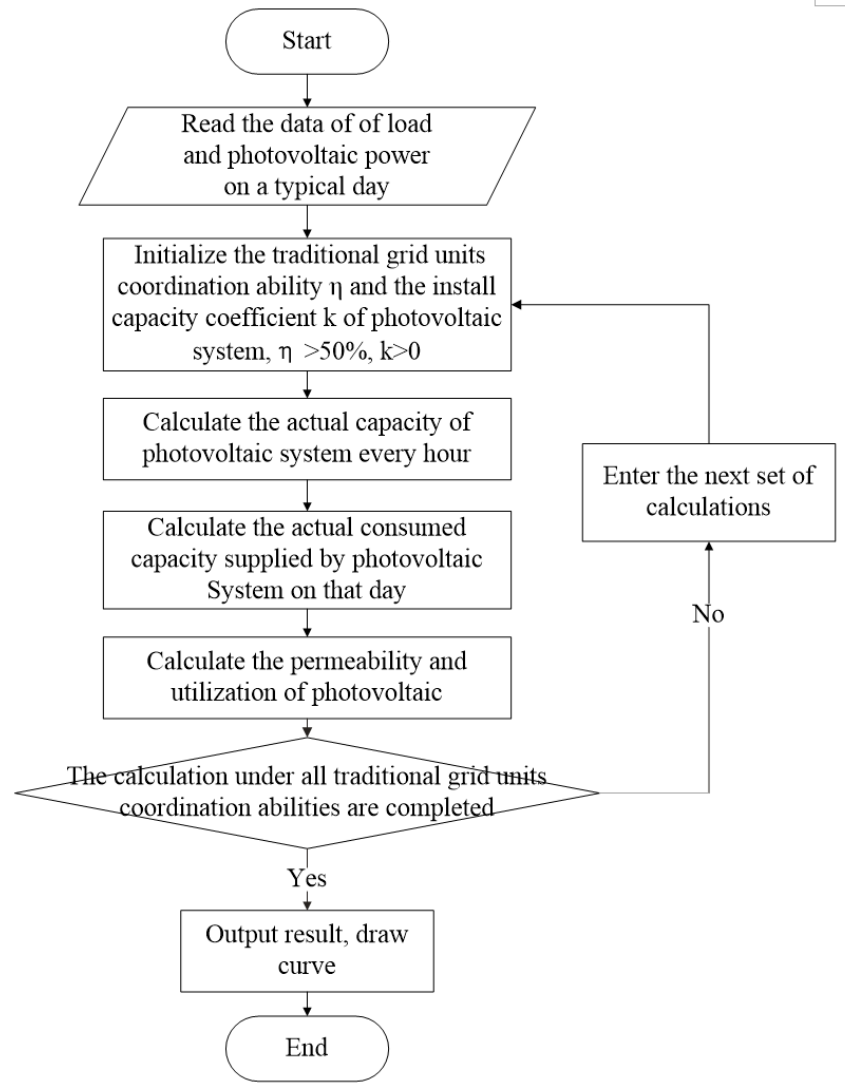

(4) Model analysis

Fig. 2 The flow chart of calculation

Comparing the actual data of the load on the selected typical day with the install capacity of photovoltaic system, it was deducted that the photovoltaic system in this project took its effect on the 
supplement for the electricity. Even if the project only displayed the role of cutting the daily peak at noon of the strongest light radiation, which couldn't meet all the demands of the electricity.

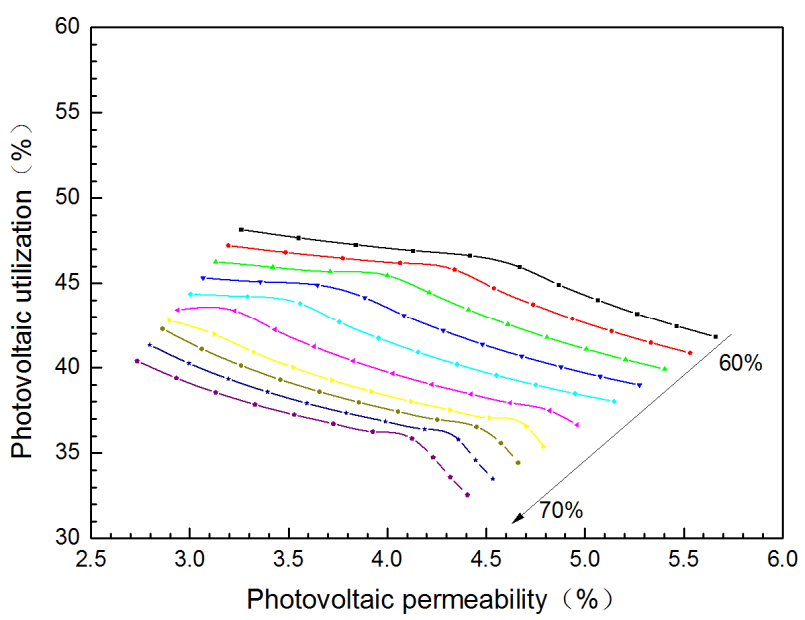

Fig. 3 The relationship between the permeability and utilization of photovoltaic under different traditional grid units coordination abilities

As shown in Fig.3, as a whole, the permeability of distributed photovoltaic generation in this project was only in the range of $2.5 \% \sim 6 \%$ which was far from reaching high permeability level. The utilization of photovoltaic decreased with the permeability of photovoltaic. The traditional grid units coordination ability was greater, and the utilization of photovoltaic was lower, and the light-discarded rate was higher. What's more, when the traditional grid units coordination ability changed in the range of $60 \% \sim 70 \%$, the utilization of photovoltaic remains in the region of 30\% 50\% and the highest light-discarded rate didn't exceed 70\% which appeared under the maximum traditional grid units coordination ability. Therefore, it was directly reflected that although distributed grid-connected photovoltaic generation could reduce the daily peak, it had disadvantageous restriction factors in traditional power grid in Fig.3.

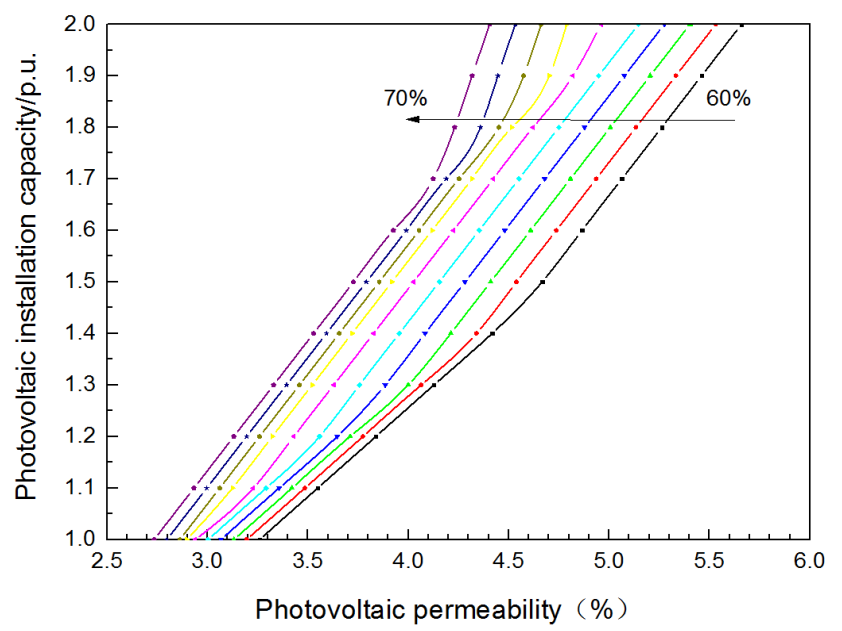

Fig. 4 The relationship between the permeability and the install capacity of photovoltaic under different traditional grid units coordination abilities

It was displayed that the permeability of photovoltaic increased with the install capacity in the case of the low permeability level of distributed grid-connected photovoltaic generation as shown in Fig. 4. However, due to the limitation of the traditional grid units coordination ability, the install capacity of photovoltaic system increased and accordingly the traditional grid units coordination ability improved would do a favor to the permeability of photovoltaic. It was directly reflected that the permeability level of distributed grid-connected photovoltaic generation could make a progress by improving the structure, optimizing the operation mode of traditional generation units and other measures to expand their stable operating range in Fig. 4. 


\section{Conclusions}

Compared with the permeability level of distributed grid-connected photovoltaic generation in Germany and the United States, the level in our country was still low. But with the strong motivation of country and government incentive mechanism, the boom in the photovoltaic generation appeared. The relationship of the permeability, utilization and install capacity of utilization under the condition of the limitation of the traditional grid units coordination ability was analyzed by taking a project of distributed grid-connected photovoltaic generation in Shanghai as an example in this paper. The utilization and the permeability of photovoltaic changed with traditional grid units coordination ability. And the permeability of photovoltaic nearly increased linearly with the install capacity of photovoltaic system. Meantime, enhancing the traditional grid units coordination ability was helpful for improving the utilization of photovoltaic utilization and reducing the light-discarded rate and the unit cost of photovoltaic system. Therefore, the transformation of traditional generation units can make it better to adapt to the development of new energy era, which have a positive promoting role in the development of new energy and improving the energy structure of our country.

\section{Acknowledgements}

This work was financially supported by the technology project of State Grid Shanghai Municipal Electric Power Company (527006160005).

\section{References}

[1] W. Zhou,Y. Zhang, C. J. Xia, Q. Wang: Power System Protection Control Vol. 38 (2010), p. 1.

[2] F. F. Lv, H. X. Yin: Electrical Engineering Vol. 5 (2013), p. 6.

[3] C. Liu, S. Ma, C. Dong, Y. H. Huang, Y. F. Wang, J. T. Zhang, D. Andreas: Power System Technology Vol. 39 (2015), p. 1765.

[4] X. Liu, J. J. He: Energy Vol. 4 (2016), p. 100.

[5] W. J. Wang, S. C.C Wang: Bulletin of Chinese Academy of Sciences Vol. 31 (2016), p. 165.

[6] B. Zhao, B. W. Hong, X. H. Ge: East China Electric Power, Vol. 38 (2010), p. 1388.

[7] B. Zhao, X. S. Zhang, B. W. Hong: Electric Power Automation Equipment Vol. 32 (2011), p. 95. 